\section{A Theoretical Need for Applying Flipped Learning to STEAM Education}

\author{
Young Kyung Jung ${ }^{1}$, Hyeonmi Hong ${ }^{2}$ \\ ${ }^{1}$ Seoul Dongja Elementary School, Seoul, Korea \\ ${ }^{2}$ Education Research Institute, Seoul National University, Seoul, Korea
}

This paper addresses the current problems of STEAM education and suggests a solution to solve one of the problems through adopting a method from Flipped Learning. Through the meticulous literature review, comparison, and analysis on STEAM and Flipped Learning, it will be shown that the methodology of Flipped Learning complements the weaknesses in STEAM. The conclusion is that since there is a theoretical need for applying Flipped Learning to STEAM, further research needs to be carried out to apply flipped learning in STEAM classes.

Keywords: STEAM; Convergence; Flipped Learning; Educational methodology

\section{INTRODUCTION}

The goal of education used to be to train individuals to have certain skills and knowledge in order that they may have a higher chance of success in the future. Due to the rapid technological advancement in the last century and since the start of the new millennial, the future is more unpredictable. The goal of education now is to train individuals to be flexible and adaptable to the unpredictable future (Rychen \& Salganik, 2003). In parallel with such a change, the need for pedagogical research has also increased (Evensen \& Hmelo, 2000).

What is more important is that in the face of these changes, the limitations of existing teaching and learning methods are being revealed (Gilboy et al., 2015; Bazler \& Sickle, 2017). The traditional teaching and learning method in the classroom is in need of improvement or changes. The manner in which the teacher communicates knowledge unilaterally to the students is less likely to make educational impact for the students who are already familiar with the culture of acquiring various pieces of knowledge from the internet and communicating with people in various communities online (Barrett, 2012; Herreid \& Schiller, 2013; Roehl et al., 2013). The limitations and new demands in the field of education have advanced discussions on alternative paradigms of education (Hidi \& Harackiewicz, 2000).

STEAM, which stands for Science, Technology, Engineering, Arts, and Mathematics, is a new educational system which hopes to prepare individuals for the unpredictable future. Originally based on STEM (which is without the Arts curriculum), STEAM aims to educate individuals to be able to think in a divergent and convergent manner (Bazler \& Sickle, 2017). According to the results of research, STEAM appears to enable creative and critical thinking in humanities education (Ferrall, 2011). Therefore, it better educates individuals to live curiously and creatively with the knowledge on arts, science, and mathematics (Spector, 2015; Yakman \& Lee, 2012).

However, STEAM has many problems too despite its advantages. It is true that the teachers who implemented STEAM recognize the importance of the integrated education method (Noh \& Ahn, 2012). However, it has been pointed out that not only do the teachers need less work in implementing STEAM, but also the teachers do not seem to know the difference be-

\section{Review Article}

pISSN 2288-8675 · elSSN 2508-9145

J Probl Based Learn 2020;7(1):42-49

https://doi.org/10.24313/jpbl.2020.00213

Received: March 16, 2020

Revised: April 20, 2020

Accepted: April 30, 2020

Corresponding author:

Hyeonmi Hong

Education Research Institute, Seoul National University, San 56-1, Sillimdong, Gwanak-gu, Seoul, 08826, Korea

Tel: 82-2-880-7615

E-mail: hong212@snu.ac.kr
(C) Copyright 2020 International Society for Problem-Based Learning

(c) This is an Open Access article distributed under the terms of the Creative Commons Attribution Non-Commercial License (http://creativecommons.org/licenses/ by-nc/4.0/) which permits unrestricted non-commercial use, distribution, and reproduction in any medium, provided the original work is properly cited. 
tween STEAM and the traditional science education (Park et al, 2016). Therefore, in order to solve these difficulties faced by teachers and to fulfill the purpose of STEAM successfully, it is necessary to expand the class time, to diversify the class space, to use various teaching materials in a communicative way, to secure communication space between teachers and learners, to provide individualized learning materials which take individual differences of learners into account (Lim, Kim, \& Lee, 2014).

In order to solve the difficulties encountered by the teachers who want to continue to teach STEAM, such as the lack of time for the education, and the difficulty of knowing exactly how to proceed with the class, this paper suggests Flipped Learning as a methodology to complement STEAM. This review paper focuses on the need for learners and teachers to adopt the methodology of Flipped Learning in order to effectively achieve the goal of STEAM.

\section{WHAT IS STEAM?}

STEM, an educational system that the U.S. actively introduced since the late 20th century, aims to advance science and mathematics education as well as to focus on convergence between disciplines of science. Its goal is to enhance students' interest in science, technology, engineering and mathematics as well as to advance technical literacy (Breiner et al., 2012). Traditional science education, which excludes the humanities, plays an excellent role in providing knowledge of mathematics and nature and skill in science and technology, but it was not effective in developing the creativity of scientists or to discover and solve interdisciplinary problems. (Madden et al., 2013). To overcome this problem, the movement to include humanities and arts in science-based education has been attempted by many scholars (Ghanbari, 2014).

STEAM was first introduced in the U.S. because the American Academy of Sciences realized that interest in STEM education was declining (National Academies, 2007). Yakman (2008), who first proposed the structure of STEAM, criticized STEM for lacking convergence even though STEM adopts an integrated approach to teaching and learning academic concepts in science, technology, engineering, and mathematics. She believed that STEAM was an optimal education system that can provide a wholly convergent structure of learning experience which cannot be achieved by the STEM only. According to Bazler and Sickle (2017), STEAM education is currently an emerging educational model in the U.S., because it purports to overcome the weaknesses of STEM education.

The characteristic of STEAM is the introduction of the concept of convergence between basic subjects especially with the arts curriculum, which has not been actively pursued in the traditional curriculum. Convergence is one of the most important strategies for solving complex problems and solving complex intellectual problems in new fields in the 21st century. The students need to be prepared for the future by learning how to integrate ideas, approaches, and technologies from various knowledge fields (National Research Council, 2014). Therefore, STEAM aims to develop creative and future oriented talent by presenting a curriculum that can integrate individualized knowledge into one.

\section{IMPORTANCE OF CONVERGENCE IN STEAM}

The characteristics of convergence in STEAM can be summarized as follows. First, it is learning-oriented. Chopp (2014) suggests a conceptual concept of knowledge design that helps students learn about individual subject matter in a convergent way. Knowledge acquisition design aims to "grant creativity and clarity to the center of learning and learner attitudes" by accepting a new learning platform and recognizing the power of convergence of visualization power and knowledge (Chopp, 2014).

Second, it is dialectical. It gives emphasis on the process by which learners find and pioneer knowledge acquisition on their own. The process of searching for knowledge is only possible when the learners themselves ask questions from their curiosity about the knowledge and find an answer to the questions. The nature of this process is dialectical. As found in years past, teaching methods focused on teaching and learning in a dialectical way emphasized the importance of discussing and participating actively with other learners (Greeno, Collins \& Resnick, 1996).

Third, various educational means are utilized. As found in past decades, in order to effectively integrate knowledge, it is necessary not only to teach using various media, but also to apply knowledge under various social contexts (Brown, Collins \& Duguid, 1989). It is true that there have been many attempts to improve the effectiveness of learning using various media, not limited to textbooks in education (Mayer \& Moreno, 2010). Attempts to actively utilize various media such as the internet, video, and mobile learning to construct convergent knowledge are characteristics of STEAM.

\section{APPLICATION OF INSTRUCTIONAL DESIGN PRINCIPLES OF STEAM}

The following instructional design principles summarize the re-conceptualization and restructuring of the curriculum in the 
STEAM fields with various pedagogical teaching strategies in order to solve the needs and tasks of the 21st century. Palou et al. (2015) applied STEAM to construct a core support system for engineering students who would be prepared for the 21st century. They created a learner-centered learning environment and reconstructed the basic courses in chemistry and environmental engineering.

Coffland and Xie (2015) likewise describe the experience of teaching mathematics curriculum based on four skills required by the 21st century: Communication, Collaboration, Critical thinking, and Creativity (Partnership for 21st Century, 2011). Through this curriculum, they have enabled learners to face and experience the problems arising in real life in order to promote self-learning and to combine academic knowledge with real-life problems.

Christensen and Knezek (2015) adopted an active learning approach. The researchers proposed an attempt to actively include technology into the middle school science curriculum based on the STEAM skills required by the 21 st century. Student-centered active learning has been shown to contribute to a long-term retention of knowledge and a deeper understanding of the subject (Akinoglu \& Tandogan, 2007).

Furthermore, Aschbacher, Ing \& Tsai (2013) suggest that if the content that students learn at school is more relevant to students personally and if the content is related to the future, the students' become more drawn to the subject and learn more effectively and faster. Christensen \& Knezek (2015) found out that with an active learning approach, students' academic achievement increases and positively affects students' attitudes toward science and related subjects.

Based on such studies, it can be concluded that STEAM is appropriate for preparing students for the future (D'Mello et al., 2014). In addition to this, with STEAM, students will be able to be more creative in the process of constructing knowledge in a convergent way. In addition, the STEAM focus introduces a way to acquire knowledge connectively through interaction and cooperation among learners, so that it is expected to increase the communication effect among learners.

\section{SUGGESTED STEAM EDUCATIONAL STRATEGIES TO IMPROVE LEARNING}

Ifenthaler et al. (2015) designed engineering education using a collaborative learning strategy. They suggest that the use of co-operative strategies has changed the attitudes of learners receiving engineering education, their thinking about themselves, and the activeness of a team. They published a case study that examined the effects of the learning organization model on attitude change, self-awareness, and organizational structure of student learning engineering (Mistree et al., 2014). This new curriculum emphasizes the capabilities and possibilities of individuals developed in a collaborative learning model and environment. In this model, learning took place at three levels: Individual learning, team-based learning, and group-based learning. Many of these curriculum strategies are designed to support STEM education, but they can also be applied to STEAM education.

Second, they suggest that, during the class teachers should organize students into small groups for in-class class activities or for activities outside of class. Unlike the traditional strategy of constructing the contents of the lesson centered on the topic decided by the teacher, the students can present the tasks, problems, questions, difficulties and contents contained in the topics to the students through one or more scenarios. Scenario-based approaches can be implemented under a variety of models, including problem-oriented strategies and project-driven strategies. Based on a scenario-based approach, students solve problems by presenting specific situations and scenarios in which problems are presented, and teachers are provided with tools to further develop the scenarios and the content. There is a lot of evidence to support the overall scenario-based approach, but there are a few drawbacks to the strategy of organizing students into small groups to increase classroom efficiency and performance. Teachers applying the scenario-based approach frequently have to organize students into small groups and test applicability of student led-group process to scenario-based strategies (Prince \& Felder, 2006).

Based on these findings, Shen, Jiang \& Liu (2015) proposed the following four STEM education strategies to improve students' lifelong learning skills.

1. Designing activities to engage and motivate students in active learning: The essence of this strategy is to develop activities that help students take more responsibility for learning by creating student-led environment. These activities can be considered in various ways, such as demonstrating interesting scientific phenomena, writing science content related to a student's personal life, extending learning to external learning areas, and linking science to other exciting academic disciplines or entertainment.

2. Using a scenario-based content: A scenario-based approach represents a broad educational strategy that provides learning materials to students over longer periods, centered on one or more scenarios. These cases can often be classified as problem-based, project-based, case-based, survey-based, or taskbased. 
3. Organizing Students Focused on Collaboration: This practice follows a strategy for organizing small groups and organizing learning communities. Collaborative work can stimulate interest in class by interacting face-to-face with students in various classes, before and after classes, or interacting virtually through the Internet.

4. Conduct research: This strategy is to encourage students to develop research that is of interest to them under the supervision of a teacher.

\section{REPORTED PROBLEMS OF STEAM}

Despite the advantages of STEAM, it has been reported that the teachers face a lot of difficulties when applying the STEAM in their classrooms. Lim, Kim \& Lee, (2014) examined elementary school teachers' opinions and experiences of teaching STEAM, and found that they think there is lack of STEAM activities and they face difficulties in preparation for STEAM classes. Although most teachers see the need for teaching STEAM classes, the lack of instructional materials discourage them from actively teaching STEAM. In addition, Lee, Park \& Kim, (2013) report that there is shortage of classroom hours for teachers

to effectively carry out the STEAM classes. For the integrated curriculum to be delivered requires teachers to have a lot of knowledge and plan student activities. It takes a lot of time to carry out a long-term project, but the current number of assigned teaching hours for STEAM is not enough for such activities. Shin \& Han (2011) pointed out that there is difficulty for teachers to integrate educational elements and activities through STEAM when they conducted STEAM classes.

The potential difficulties that teachers face regarding STEAM are summarized in three points. First, there is a difficulty in lack of class time. STEAM not only requires a lot of knowledge and activities in the integrated subject matter to be delivered, but also demands a long enough classroom time to carry out the activities properly. Therefore, STEAM classes are not effective enough to achieve its original goal. Teachers may feel further burdened in overcoming the difficulties. Second, it is difficult for teachers to prepare class materials for STEAM. In fact, it is very difficult for the teachers to make the STEAM materials in accordance with the students' interest and level. Third, students are not gaining enough knowledge that is supposed to be interdisciplinary and convergent. At the core of STEAM is to acquire interdisciplinary knowledge and to transfer such knowledge into produce more creativity. The activities conducted in STEAM are for acquiring convergent knowledge, but the problem is that learners are often more interested in the activities themselves rather than the inter- disciplinary knowledge. These difficulties may be due to various reasons, but it is especially important to notice that there is a lack of communication channels to check whether learners really acquire interdisciplinary skills, and that the level of individual learners is not properly reflected in the actual classes either.

The current problems in STEAM, such as shortage of teachers' time for preparing the STEAM classes and difficulties in coming up with classroom activities, can be complemented by introducing the methodology of Flipped Learning. Flipped Learning can be adopted to extend class time by providing opportunities to learn basic knowledge and concepts before STEAM class begins. In addition, the use of various high-tech media outside the classroom leads to the diversification of the classroom space. With the various teaching materials online, learners effectively absorb the knowledge according to their pace and preference. It enables individuals to change their learning speed according to their learning ability.

\section{WHAT IS FLIPPED LEARNING?}

Flipped learning is an alternative to the teacher-centered, traditional way of teaching. It emphasizes engaging activities among students and interactions between teachers and students (Hamdan et al., 2013; Strayer, 2012). Traditional classes taught basic concepts and knowledge in the classroom and applied learner-centered activities as homework (McCarthy \& Anderson, 2000). In contrast, Flipped Learning is a process of learning basic knowledge and concepts outside the classroom (Love et al., 2014). By "flipping" the classroom, students participate in various problem-solving activities based on learners' interest and level of need in the classrooms, which is an innovative proposal for teaching methods (Bergmann \& Sams, 2013).

In addition, Flipped Learning dramatically changes the content and aspects of classroom instruction (Bergmann \& Sams, 2014). Flipped Learning allows students to voluntarily solve problems by cooperating with each other (Jamaludin \& Osman, 2014). The role of the instructor is not exclusively limited to lecturing, but expanded to providing feedback and advice to students.

Bergmann \& Sams (2013) believe that the most important aspect in Flipped Learning is the meaningful learning activity that occurs in the face-to-face classrooms. Also, it is emphasized that the center of learning is not the teacher but the activities of the students and the students are taking into consideration the important activities to be done in the classroom. Strayer (2012) argues that the most important stage of Flipped Learning is the activity of expanding and deepening the concepts learned through video and various mediums in pre-classrooms in real classrooms. 
In addition to the theoretical studies on Flipped Learning, the educational effects of Flipped Learning can be summarized in terms of improvement in learning ability among students (Saban, 2013). Flipped Learning improves self-directed learning ability, students' interest in learning, ability to understand the contents, problem-solving ability, and self-confidence. In addition, the aspects of cooperative learning, collaborative learning are emphasized by encouraging students to discuss problem-solving activities with each other, sharing knowledge among colleagues, and even teaching peers (O’Flaherty \& Phillips, 2015).

To sum up, Flipped Learning, which has an educational effect on the cognitive dimension of students which broadens the level of knowledge and provides opportunities for mutual knowledge exchange among them, is becoming a popular educational approach to fostering talented individuals for the 21 st century (Newman et al., 2016).

\section{THE FOUR PILLARS OF FLIPPED LEARNING}

Sams \& Bergmann (2014), who have been leading the study of Flipped Learning, have established The Flipped Learning Network. According to the Flipping Learning Network Board, the characteristics of Flipped Learning are compared to the four pillars: Flexible environment, a Learning culture, Intentional content, and a Professional educator. The detailed characteristics are as follows.

First, Flipped Learning, which provides a flexible environment, accommodates a variety of learning methods. Teachers need to physically reconfigure the learning space for collaborative learning or individual learning in the process of optimizing the class. It is a feature of Flipped Learning to create a flexible space where learners can learn whenever and wherever they need. Furthermore, teachers who flip the classroom tend to be flexible in coping with learners' learning plans and evaluations.

Second, Flipped Learning helps change the classroom climate into a learner-centered learning culture. In traditional teacher-centered instructional models, teachers had the authority to distribute information. In the Flipped Learning model, however, the lessons flexibly change with the learners. Such changes induce the learner to explore deeply on the subject and provide a rich learning experience. As a result, students engage in knowledge formation and evaluate their learning in a personally meaningful way.

Third, teachers who perform Flipped Learning continue to contemplate how to use the Flipped Learning model efficiently to help students understand the knowledge and the goal of edu- cation. Teachers can optimize class time to accommodate learner-centered, active-learning strategies, grade levels, and the curriculum.

Fourth, in Flipped Learning, teachers have professional knowledge of technology as well as being knowledgeable on the content. The role of the professional teacher in the Flipped Classroom is more important than the traditional classroom. During class time, teachers constantly observe students, provide them with instantaneous feedback, and assess their work. Teachers are reflective in the actual classrooms and engage in constructive criticism in relation to each other teachers to improve their teaching methodologies.

\section{THEORETICAL ADVANTAGES OF COMBINING STEAM WITH FLIPPED LEARNING}

Flipped Learning, which is being used as a new teaching method in the current education field, can be a useful method to implement the problems reported in STEAM. The first advantage is that Flipped Learning provides teachers with pre-learning materials and utilizes the cloud computing environment to enable easy learning through smartphones and tablet PCs regardless of where the students are and what time the students want to study. In addition, the pre-learning content itself provides information not only about the basic knowledge but also about how to practically implement the use of knowledge for students. This enables learner-centered education by helping students participate in real classroom activities more actively.

Park (2014) state the advantages of Flipped Learning as follows. First, students learn the concept of knowledge in advance and can concentrate on the STEAM activities in school classes. Second, teachers can efficiently utilize the STEAM program by applying the teaching strategies or class models suitable for the STEAM education through Flipped Learning.

Nowadays, Flipped Learning is introduced as a new learning system for this digital generation because students are already familiar with the use of digital devices, can multitask, and are capable of instant online communication. The most important aspect is the fact that it is student-centered. It is personalized learning. Student-centered classrooms use Dewey's philosophy (Dewey, 1916) - the constructivist education paradigm as a philosophical basis for designing Flipped Learning (Ryder, 2006). In other words, Flipped Learning plays an effective role in establishing a student-centered classroom environment in which students select and construct content of their own. They become initiative as they become facilitators of knowledge, contrary to the tradi- 
tional classroom teaching methods in which teachers are the center of the classroom.

Flipped Learning requires the teacher to constantly check and verify his or her class, because the teacher requires the student to rebuild the existing curriculum so that the students actively participate in the class. Through this process, the teacher prepares the lesson considering the interest, concern, and readiness of each student while considering the universal design for learning.

The advantages of adopting Flipped Learning into STEAM based on methodological characteristics are as follows. First, it allows teachers to balance the need to handle and deliver large volumes of learning content and the need for students to build meaning through interaction with the content (Bishop \& Verleger, 2013). Second, because students actively use and apply knowledge in the classrooms, Flipped Learning can be seen by the teacher as a natural part of the students' overcoming weaknesses in the learning process (Butt, 2014). Third, Flipped Learning can increase student participation and motivation (Critz \& Knight, 2013). Fourth, Flipped Learning can improve teacher-student and peer interaction (Gaughan, 2014).

The main advantage of Flipped Learning is that it can flexibly adapt to a variety of learning methods (Roehl, Reddy \& Shannon, 2013; Schwartz, 2014). Unlike traditional classroom lectures, students are free to choose where and how to view the recorded lecture material before class (Forsey, Low \& Glance, 2013). Teachers who have introduced Flipped Learning can no longer teach in class, so they can help them learn more effectively by developing higher-level learning methods and applying the practical skills (Stayer, 2012).

According to Hamdan et al. (2013), most Flipped Learning studies point out that students' perceptions and learning effects through Flipped Learning were generally positive and preferred classroom activities with interactions rather than lectures. Bergmann \& Sams (2013) also report that Flipped Learning has proven to be an effective learning method for children with diverse learning abilities and environments. Davices, Dean \& Ball (2013) also show that classes that adopted Flipped Learning in college had higher academic achievement in those who did not. Flumerfelt \& Green (2013) found that Flipped Learning has a positive effect on the academic achievement in high school.

In summary, using Flipped Learning, various kinds of advanced media are utilized, interaction between learners is encouraged, various learner-centered activities are performed, and communication between teachers and students is increased through such an interaction-based learning methodology. By actively utilizing these characteristics of Flipped Learning, the teachers of STEAM will be able to solve the problems that they faced: they will not have shortage of time teaching the basic knowledge and preparing the class materials and convergent knowledge of STEAM.

\section{CONCLUSION}

STEAM is aimed at fostering talented individuals who are able to creatively converge knowledge to creatively converge fragmented knowledge. However, due to lack of time for teachers and effective methodology, it failed to enable students be creative and reconstruct the knowledge. One solution to this problem is to adopt the learner-centered methodology, Flipped Learning. It is a teaching method that can lead to integration of such knowledge. The educational model which combines STEAM with Flipped Learning motivates a need for providing instructional design to promote learners' activity, responsibility, mutual understanding, and mutual trust among each other. Applying Flipped Learning for STEAM in the current education system, which requires students to be creative and flexible, will be able to not only positively change the interests and attitudes of learners, but also enhance creativity by creating a room for convergence of knowledge (Lewis, 2015).

\section{REFERENCES}

Akinoglu, O., \& Tandogan, R. O. (2007). The effects of problem-based active learning in science education on students' academic achievement, attitude and concept learning. Eurasia Journal of Mathematics, Science \& Technology Education, 3(1), $71-81$.

Aschbacher, P. R., Ing, M., \& Tsai, S. M. (2013). Boosting student interest in science. Kappan Magazine, 95(2), 47-51.

Barrett, D. (2012). How 'Flipping' the classroom can improve the traditional lecture. The Chronicle of Higher Education, 58(25), 16-18.

Bazler, J., \& Meta Van, S. (2017). Cases on STEAM Education in Practice. Hershey: IGI Global.

Bergmann, J., \& Sams, A. (2013). Flip your students' learning. Educational Leadership, 70(6), 16-20.

Bergmann, J., \& Sams, A. (2014). Flipped learning: Gateway to student engagement. Washington D.C.: International Society for Technology in Education.

Bishop, J. L., \& Verleger, M. A. (2013). The flipped classroom: A survey of the research. 120th American Society for Engineering Education National Conference Proceedings. Atlanta, GA.

Breiner, J. M., Harkness, S. S., Johnson, C. C., \& Koehler, C. M. (2012). What is STEM?: A discussion about conceptions of 
STEM in education and partnerships. School Science and Mathematics, 112(1), 3-11.

Brown, J. S., Collins, A., \& Duguid, P. (1989). Situated cognition and the culture of learning. Educational Researcher, 18, 32-42.

Butt, A. (2014). Student views on the use of a flipped classroom approach: Evidence from Australia. Business Education \& Accreditation, 6(1), 33-44.

Chopp, R. (2014). Remaking, renewing, reimagining: The liberal arts college takes advantage of change. In R. Chopp, S. Frost \& D. H. Weiss (Eds.), Remaking college: Innovation and the liberal arts (pp. 13-24). Baltimore: The Johns Hopkins University Press.

Christensen, R., \& Knezek, G. (2015). Active Learning Approaches to Integrating Technology into a Middle School Science Curriculum Based on 21st Century Skills. In X. Ge, D. Ifenthaler \& J. M. Spector (Eds.), Full steam ahead: Emerging technologies for STEAM education (pp. 17-38). New York: Springer.

Coffland, D., \& Xie, Y. (2015). The 21st Century Mathematics Curriculum: A Technology Enhanced Experience. In X. Ge, D. Ifenthaler \& J. M. Spector (Eds.), Full steam ahead: Emerging technologies for STEAM education (pp. 311-331). New York: Springer.

Critz, C. M., \& Knight, D. (2013). Using the flipped classroom in graduate nursing education. Nurse Educator, 38(5), 210-213.

D’Mello, S., Lehman, B., Pekrun, R., \& Graesser, A. (2014). Confusion can be beneficial for learning. Learning and Instruction, 29, 153-170.

Davies, R. S., Dean, D. L., \& Ball, N. (2013). Flipped the classroom and instructional technology integration in a college-level information systems spreadsheet course. Educational Technology Research \& Development, 61, 563-580.

Dewey, J., \& Dewey, E. (1915. E.(1985)). Schools of tomorrow. John Dewey: The middle works (1899-1924). 8, 205-404.

Dewey, J. (1916). Democracy and education. 2008th ed. volume 4. Toledo, Ohio, USA: Student handouts. Inc.(Web: 9 Oct. 2011).

Evensen, D. H., \& Hmelo, C. E. (2000). Problem-based learning: A research perspective on learning interactions. Mahwah, NJ, Lawrence Erlbaum Association.

Ferrall, V.E. (2011). Liberal arts at the brink. Cambridge: Harvard University Press.

Flumerfelt, S., \& Green, G. (2013). Using Lean in the Flipped Classroom for At Risk Students. Educational Technology \& Society, 16(1), 356-366.

Forsey, M., Low, M., \& Glance, D. (2013). Flipping the sociology classroom: Towards a practice of online pedagogy. Journal of Sociology, 49(4), 471-485.

Gaughan, J. E. (2014). The flipped classroom in world history.
History Teacher, 47(2), 221-244.

Ghanbari, S. (2014). STEAM: The wave of the future embedded in ideals of the past. The STEAM Journal, 1(2), Article 27. http://scholarship.claremont.edu/steam/vol1/iss2/27/. Accessed 1 January 2018.

Gilboy, M. B., Heinerichhs, S., \& Pazzaglia, G. (2015). Enhancing student engagement using the flipped classroom. Journal of $\mathrm{Nu}-$ trition Education and Behavior, 47(1), 109-114.

Greeno, J. G., Collins, A. M., \& Resnick, L. B. (1996). Cognition and learning. In D. C. Berliner \& R. C. Calfee (Eds.), Handbook of educational psychology (pp. 15-46). New York, Macmillan Library Reference USA.

Hamdan, N., Mcknight, P., Mcknight, K., \& Arfstrom, K.M. (2013). The flipped learning model: A white paper based on the literature review titled a review of flipped learning. H. R 5116111th Congress: America COMPETES Reauthorization Act of 2010.

Herreid, C. F., \& Schiller, N. A. (2013). Case studies and the flipped classroom. Journal of College Science Teaching, 42(5), 62-66.

Hidi, S., \& Harackiewicz, J. M. (2000). Motivating the academically unmotivated: A critical issue for the 21st century. Review of educational research, 70(2), 151-179.

Ifenthaler, D., Siddique, Z., \& Mistree, F. (2015). Designing for Open Innovation: Change of Attitudes, Self-Concept, and Team Dynamics in Engineering Education. In X. Ge, D. Ifenthaler \& J. M. Spector (Eds.), Full steam ahead: Emerging technologies for STEAM Education (pp. 201-217). New York: Springer.

Jamaludin, R. \& Osman. (2014). The use of a flipped classroom to enhance engagement and promote active learning. Journal of Education and Practice, 5(2), 124-131.

Lee, J., Park, H., \& Kim, J. (2013). Primary Teachers' Perception Analysis on Development and Application of STEAM Education Program. Elementary Science Education, 32(1), 47-59.

Lewis, A. (2015). Putting the "H" in STEAM: Paradigms for Modern Liberal Arts Education. In X. Ge, D. Ifenthaler \& J. M. Spector (Eds.), Full steam ahead: Emerging technologies for STEAM Education (pp. 259-275). New York: Springer.

Lim, S., Kim, Y., \& Lee, T. (2014). Analysis of Elementary School Teachers` Perception on Field Application of STEAM Education. Journal of Science Education, 38(1), 133-143.

Love, B., Hodge, A., Grandgenett, N., \& Swift, A. W. (2014). Student learning and perceptions in a flipped linear algebra course. International Journal of Mathematical Education in Science and Technology, 45(3), 317-324.

Madden, M. E., Baxter, M., Beauchamp, H., Bouchard, K., Habermas, D., \& Huff, M., et al. (2013). Rethinking STEM education: 
An interdisciplinary STEAM curriculum. Procedia Computer Science, 20, 541-546.

Mayer, R. E., \& Moreno, R. (2010). Techniques that reduce extraneous cognitive load and manage intrinsic cognitive load during multimedia learning. In J. L. Plass, R. Moreno \& R. Brünken (Eds.), Cognitive load theory (pp. 131-152). Lodon: Cambridge University Press.

McCarthy, J. P., \& Anderson, L. (2000). Active learning techniques versus traditional teaching styles: Two experiments from history and political science. Innovative Higher Education, 24(4), 279294.

Mistree, F., Panchal, J. H., Schaefer, D., Allen, J. K., Haroon, S., \& Siddique, Z. (2014). Personalized engineering education for the 21st century: A competency based approach. In M. Gosper \& D. Ifenthaler (Eds.), Curriculum models for the 21st century. Using learning technologies in higher education (pp. 91-112). New York: Springer.

National Academy of Sciences, National Academy of Engineering, and Institute of Medicine, Committee on Prospering in the Global Economy of the 21st Century: An Agenda for American Science and Technology, and Committee on Science, Engineering, and Public Policy, Rising Above the Gathering Storm: Energizing and Employing America for a Brighter Economic Future (Washington, DC: National Academies Press, 2007).

National Research Council. (2014). Convergence: Facilitating Transdisciplinary Integration of Life Sciences, Physical Sciences, Engineering, and Beyond. Washington (DC): National Academies Press(US).

Newman, G., Kim, J. H., Lee, R. J., Brown, B. A., \& Huston, S. (2016). The Perceived Effects of Flipped Teaching on Knowledge Acquisition. Journal of Effective Teaching, 16(1), 52-71.

Noh, S., \& Ahn, D. (2012). A study on the theoretical-practical changes of present education in view of the academic convergence. The Journal of Educational Research, 10(1), 67-88.

O'Flaherty, J., \& Phillips, C. (2015). The use of flipped classrooms in higher education: A scoping review. The Internet and Higher Education, 25, 85-95.

Palou, E., et al. (2015). Critical Support Systems to Enhance the Development and Assessment of 21st Century Expertise in Engineering Students. In X. Ge, D. Ifenthaler \& J. M. Spector (Eds.), Full steam ahead: Emerging technologies for STEAM Education (pp. 217-247). New York: Springer.

Park, K. (2014). Exploration of the possibility of Flipped Learning in social studies. Korean Social Studies Education, 53(3), 107120.
Park, H., Byun, S., Sim, J., Baek, Y., \& Jeong, J. (2016). A Study on the Current Status of STEAM Education. Journal of the Korean Association for Science Education, 36(4), 669-679.

Prince, M. J., \& Felder, R. M. (2007). The many faces of inductive teaching and learning. Journal of College Science Teaching, 36(5), 533-568.

Roehl, A., Reddy, S. L., \& Shannon, G. J. (2013). The flipped classroom: An opportunity to engage millennial students through active learning strategies. Journal of Family \& Consumer Sciences, 105(2), 44-49.

Roehl, A., Reddy, S. L., \& Shannon, G. J. (2013). Highlights from the OECD Project Definition and Selection Competencies: Theoretical and Conceptual Foundations (DeSeCo).

Ryder, M. Instructional Design Models. Retrieved from the School of Education, University of Colorado Denver website http:// carbon.ucdenver.edu/-mryder/itc/idmodels.html.

Saban, Y. (2013). The flipped classroom instructional module. In Proceedings of the 18th Annual TCC Worldwide Online Conference Manoa, Hawaii.

Schwartz, T. A. (2014). Flipping the statistics classroom in nursing education. The Journal of nursing education, 53(4), 199-206.

Shen, J., Jiang, S., \& Liu, O. (2015). Reconceptualizing a College Science Learning Experience in the New Digital Era: A Review of Literature. In X. Ge, D. Ifenthaler \& J. M. Spector (Eds.), Full steam ahead: Emerging technologies for STEAM Education (pp. 61-80). New York: Springer.

Shin, Y., \& Han, S. (2011). Study of the Elementary School Teachers' Perception in STEAM Science, Technology, Engineering, Arts, Mathematics). Elementary Science Education, 30(4), 514-523.

Spector, J. M. (2015). Education, training, competencies, curricula and technology. In X. Ge, D. Ifenthaler \& J. M. Spector (Eds.), Full steam ahead: Emerging technologies for STEAM Education (pp.3-14). New York: Springer.

Strayer, J. F. (2012). How learning in an inverted classroom influences cooperation, innovation and task orientation. Learning Environments Research, 15(2), 171-193.

Yakman, G., \& Lee, H. (2012). Exploring the Exemplary STEAM Education in the U.S. as a Practical Educational Framework for Korea. Journal of the Korean Association for Science Education, 32(6), 1072-1086.

Yakman , G. (2008). TEAM education: an overview of creating a model of integrative education. In Proceeding of PATT on 19th ITEEA conference, pp 335-358. 